\title{
Book Review: Shields of the Republic
}

\author{
Reviewed by Cody R. Schuette
}

\begin{abstract}
Shields of the Republic: The Triumph and Peril of America's Alliances by Mira Rapp-Hooper. Harvard University Press, 2020. ISBN: 9780-67-498295-6. 252 pp., \$23.94 (US).
\end{abstract}

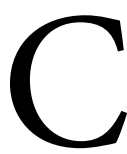
hina's and Russia's audacious and increasingly destructive transnational behavior is reducing America's relative global power. To combat this, Mira Rapp-Hooper in Shields of the Republic: The Triumph and Peril of America's Alliances argues that although the post-World War II alliance system ensured the long-peace, enhanced cooperation with neoteric responses among allies are urgently required. The stated purpose of the book is to counter the recent rise of the populist anti-alliance rhetoric and demonstrate how and why alliances must adapt to contemporary great power competition. As a Senior Fellow for Asia Studies at the Council on Foreign Relations and the China Center at the Yale Law School, Rapp-Hooper speaks with authority on these topics and provides pragmatic policy options. Before discussing her policy recommendations though, she leads the reader through an objective and detailed analysis on the benefits of alliances, their place in American foreign policy, and why the current anti-alliance rhetoric only undermines American standing.

Rapp-Hooper begins by providing the initial logic of alliances and describes their benefits over the past sev- en decades. Supported by declassified government documents from the Cold War era, alliances offered the United States forward defense of the homeland, deterrence against large-scale conflict, the assurance of support, and varying degrees of control of allies. Her persuasive analysis, often relying on counterfactual evidence, concludes alliances were overall successful in their purpose, less costly than establishing and maintaining a disconnected military capacity, and marshaled allies' decades-long support of American military adventurism. However, despite the clear advantages, there is a growing base of skeptics that question alliance rationale and utility.

Rapp-Hooper makes clear that misgivings of alliances are not new, rather as old as the republic itself. However, tying to the genesis of the book, she illustrates how former President Trump repeatedly and forcefully departed from decades of mainstream bi-partisan agreement on alliances. She specifically calls out his fixation with monetary contributions and yearning for an overwhelming benefit for the United States. With multiple examples, she further spotlights how his rhetoric was often perceived as hostile towards 
allies and more comforting towards competitors. As done throughout the book, Rapp-Hooper uses sound reasoning and historical case studies to substantiate her counterargument to those "dangerously misguided" statements (2).

She convincingly shows how the former President's rhetoric could reduce allies' commitments to the United States or weaken treaties to such a point, that if the United States entered a conflict, it could enter late, with reduced combined planning and training, and require time to reverse loses. She concludes her argument by recounting that the United States has never been a victim of entrapment and is compensated appropriately for its larger financial contributions with basing access, enhanced trade benefits, and diplomatic backing on contentious foreign policy. She concisely summarizes this overall point; "American defense spending reflects our global strategy, not alliance commitments" (100). Rapp-Hooper then supplements her direct counter to the previous administration's ostensibly apprehension towards alliances by offering the historical context.

Here, she successfully weaves history, theory, and contemporary events into an informative discussion on why the United States entered alliances for the first time since the Revolutionary War. Simply, it was the rise of the Soviet Union and technological advances that ensured the United States lost its geographic buffer and therefore its "independent foreign policy" (10). Subsequently, America's grand strategy concentrated on containing the Soviet threat in Europe, primarily through the North Atlantic Treaty Organization's (NATO) collective security guarantee, and a hub and spoke alliance construct throughout Asia. By taking a realist perspective, she argues that America's strategy maintained a balance of power in $\mathrm{Eu}$ rope and Asia. This system, as beneficial as it has been, nonetheless requires amending to adequately protect against contemporary threats posed by great power competitors.

Rapp-Hooper substantiates how China and Russia are revisionist in strategy and great power rivals of the United States. She succinctly and convincingly lays out how their behavior erodes American preponderance, yet purposefully avoids triggering alliance retaliation. Rapp-Hooper terms these actions "competitive coercion" and most prominently include China's technological espionage and island-building and Russia's election interference and cyberattacks; these actions are predicted to continue at best or intensify at worst. That is the lynchpin of her argument and subsequent policy recommendations. Rapp-Hooper asserts that competitive coercion will continue not triggering American defense treaties and, consequently, require transformed defense treaties to adequately address the threat.

In the final section of the book, she offers policy recommendations. Alliances should evolve to prevent the expansion of Chinese and Russian spheres of influence within their re- 
spective geography. She argues updated treaties must account for the aforementioned non-traditional threats. Furthermore, she recommends the United States accentuates its mutual interests with allies as a catalyst to counter great power competitors. To negate Chinese actions, the United States should expand the sharing of intelligence, increase foreign military financing, and ambitiously strive for a collective defense structure, analogous to NATO, with Asian allies. Whereas in Europe, the United States should increase the transparency of political interference and address non-democratic movements to mitigate Russian actions. The collective actions of allies would then have the reciprocal benefit of increasing deterrence through strengthened relationships.

Rapp-Hooper is candid with the book's shortcomings, albeit minor: counterfactual analysis and covering all of America's alliances without a regional or time-based focus. However, this approach purposefully fills what she sees as an academic gap by providing a holistic understanding of alliances and American foreign policy. Relying on primary and secondary sources, this is an informative and persuasive book that draws from multiple academic disciplines and policy analysis to make logical arguments. The abundance of details on a range of topics remains discernable, even for the novice, especially with her intelligible writing style and end of chapter summaries. Rapp-Hooper illuminates the benefits of alliances and dispels long-standing counterarguments against their rationale, making this book relevant and suitable for students of international relations to foreign policy practitioners. 